Société d'histoire de la révolution de 1848 et des révolutions du XIXe siècle

$62 \mid 2021$

Ancêtres

\title{
Alexandre DUPONT, Une internationale blanche. Histoire d'une mobilisation royaliste entre France et Espagne dans les années 1870
}

Jean-Clément Martin

\section{CpenEdition}

Édition électronique

URL : https://journals.openedition.org/rh19/7700

DOI : $10.4000 /$ rh 19.7700

ISSN : $1777-5329$

Éditeur

La Société de 1848

Édition imprimée

Date de publication : 20 juin 2021

Pagination : 276-278

ISSN : 1265-1354

\section{Référence électronique}

Jean-Clément Martin, « Alexandre DUPONT, Une internationale blanche. Histoire d'une mobilisation royaliste entre France et Espagne dans les années 1870 », Revue d'histoire du XIXe siècle [En ligne], 62 | 2021, mis en ligne le 17 août 2021, consulté le 26 août 2021. URL : http://journals.openedition.org/ rh19/7700; DOl : https://doi.org/10.4000/rh19.7700

Ce document a été généré automatiquement le 26 août 2021.

Tous droits réservés 


\title{
Alexandre DUPONT, Une internationale blanche. Histoire d'une mobilisation royaliste entre France et Espagne dans les années 1870
}

\author{
Jean-Clément Martin
}

\section{RÉFÉRENCE}

Alexandre DUPONT, Une internationale blanche. Histoire d'une mobilisation royaliste entre France et Espagne dans les années 1870, Paris, Éditions de la Sorbonne, 2020, 419 p., $25 €$.

1 Tiré d'une thèse de doctorat, cet ouvrage marque une étape importante dans la recherche d'Alexandre Dupont, bien connu pour ses travaux sur les guerres carlistes du $\mathrm{XIX}^{\mathrm{e}}$ siècle et, plus largement, sur les guerres civiles européennes. L'objet est apparemment circonscrit à un épisode particulier et mal connu : la guerre carliste des années 1870 et son rapport avec la politique française.

Il est certainement nécessaire de rappeler que l'Espagne (comme le Portugal ou l'Italie $\mathrm{du}$ royaume de Naples) était, depuis le début $\mathrm{du} \mathrm{XIX}^{\mathrm{e}}$ siècle, en proie aux guerres intestines de plus ou moins basse intensité entre les partisans de la royauté traditionnelle et les partisans de la monarchie libérale, sans parler des plus audacieux, désireux de créer des républiques libérales. Ces conflits sont les conséquences des bouleversements introduits par la Révolution et surtout par l'Empire, qui ont chassé les souverains et popularisé des idéologies politiques inédites. Dans ces pays, des partis se sont organisés et ont été mêlés à des affrontements sporadiques, localisés mais violents, de 1815 à 1876. Ainsi les Carlistes (en Espagne, les partisans de Don Carlos et de ses successeurs), les Miguelistes au Portugal (partisans de don Miguel) et les Bourbons d'Italie (autour du dernier roi de Naples) ont-ils été impliqués dans des combats et surtout dans des mouvements de résistance et de conspiration pendant près d'un siècle, 
liés à des réseaux européens complexes et actifs couvrant toute l'Europe. La France a été particulièrement investie dans ces luttes puisque dès 1832, après l'échec de la tentative de restauration de la duchesse de Berry, les légitimistes français ont été présents au Portugal, puis en Espagne avant de se retrouver, avec des volontaires venus de toute part et notamment du Canada, dans les troupes des zouaves pontificaux pour défendre les États du pape.

3 C'est précisément dans les années 1870 que ces tentatives contre-révolutionnaires catholiques et traditionnalistes échouent mais, et c'est son originalité et son intérêt, ce livre n'entérine pas l'idée reçue qu'il ne s'est agi que de manifestations inactuelles, périmées, pour insister, au contraire, sur les perturbations qu'elles ont entraînées dans tous les grands pays européens, Grande-Bretagne, France et Prusse notamment, qui étaient engagés dans des rivalités nationalistes.

4 À côté de ce grand courant qui remodèle la carte de l'Europe, donc du monde, et qui détermine un cours nouveau pour l'histoire, ces guerres civiles autour de la légitimité monarchique rappellent que tout n'est pas complètement joué et permettent de faire le lien avec les guerres dévastatrices qui affectent la péninsule ibérique au $\mathrm{xx}^{\mathrm{e}}$ siècle. Elles incitent aussi à voir les racines des populismes actuels, en ce XXI siècle, qui s'expriment dans des régions mal intégrées économiquement et socialement. L'auteur se garde bien de ces dernières perspectives, que je prolonge peut-être inconsidérément.

5 Le livre est, logiquement, plus prudent en traitant, dans les années 1870, des rapports entre l'État français, ses représentants et les autorités municipales de l'espace pyrénéen avec les populations légitimistes ou liées aux carlistes navarrais, basques et catalans, d'une part, et avec d'autre part, la constellation complexe des carlistes militants, nobles et ruraux, installés en France ou dans les provinces du nord de l'Espagne, et leurs liens avec les autorités espagnoles et tous les corps impliqués dans les combats.

6 La localisation de cette étude ne doit pas être mal comprise. Ce qui se joue là, de part et d'autre de la chaîne pyrénéenne est bien un conflit transnational, idéologique, social et économique, qui met en jeu toutes les composantes politiques de l'Europe, qui brouille les distinctions entre politique et contrebande, qui rassemble des classes sociales très hétérogènes mobilisées pour toutes sortes de raisons, des plus élevées et des plus intellectuelles aux plus pragmatiques, puisque les communautés rurales sont concernées par ces problèmes frontaliers qui compliquent leurs habitudes séculières.

7 L'ouvrage - très pédagogiquement - commence par mettre en lumière la méconnaissance de l'histoire politique espagnole souvent résumée à quelques lieux communs avant de proposer au lecteur un aperçu des guerres carlistes et, précaution louable, une explication des composantes du carlisme. Après deux chapitres ainsi bien posés, le troisième est consacré aux relations diplomatiques difficiles entre la France théoriquement républicaine des années 1870 et l'Espagne libérale à propos des carlistes qui bouleversent tous les équilibres précaires entre les deux États. L'enchevêtrement des acteurs, aristocrates, paysans, nobles, roturiers, hommes et femmes, est impressionnant et crée des problèmes diplomatiques et politiques pratiquement insolubles.

8 Les chapitres suivants décrivent la réalité multiforme de la mobilisation et surtout insistent sur la gestion délicate des échanges frontaliers par des États incapables de définir des règles simples et même de s'imposer à des communautés habituées à des 
pratiques séculaires. À ces pratiques somme toute prévisibles, s'ajoutent les circulations d'argent, d'armes et d'informations qui sont l'objet des trois chapitres suivants. Les réseaux carlistes n'ont rien à envier à toutes les internationales qui traversent l'Europe des militants nationalistes ou socialistes du moment, mêlant les levées de fonds à la contrebande, jouant de l'information et de la propagande. Tout cela, cependant, débouche sur des opérations mal coordonnées, mobilisant modérément des populations parfois désorientées et peu préparées, d'autant plus que des volontaires étrangers viennent naïvement se battre sur un terrain inconnu. Reste alors la mémoire de ces événements et des héros et des martyrs qui se combine tant bien que mal dans la suite des guerres civiles espagnoles du $\mathrm{xx}^{\mathrm{e}}$ siècle.

9 On aura compris que ce livre excède toutes les limites géographiques et historiques dans lesquelles il est inscrit pour proposer des perspectives qui remettent en cause nos habitudes de voir l'histoire européenne tourner autour de l'établissement des nations. En ces moments de redécouverte de la complexité politique, ce livre est salutaire. 